\title{
Conformationally altered hyaluronan restricts complement classical pathway activation by binding to C1q, C1r, C1s, C2, C5 and C9, and suppresses WOX1 expression in prostate DU145 cells
}

\author{
QUNYING HONG $^{1}$, EMORY KUO $^{1}$, LORI SCHULTZ $^{1}$, ROBERT J. BOACKLE $^{2}$ and NAN-SHAN CHANG ${ }^{1,2}$ \\ ${ }^{1}$ Guthrie Research Institute, Laboratory of Molecular Immunology, 1 Guthrie Square, Sayre, PA 18840; \\ ${ }^{2}$ Section of Oral Biology, Department of Stomatology, Medical University of South Carolina, \\ School of Dental Medicine, Charleston, SC 29425, USA
}

Received July 21, 2006; Accepted September 12, 2006

\begin{abstract}
Linear non-sulfated hyaluronan (HA) does not bind complement proteins yet inhibits their hemolytic function. We have previously induced the complement inhibitory function of HA by heat treatment. However, heated HA readily loses its anti-complementary activity probably due to instantaneous interchain re-association. Here, HA solutions were heated and then freeze-dried. Compared to native HA, heated/freeze-dried HA stably restricted serum complement-mediated hemolysis via the classical pathway, in which serum $\mathrm{C} 1$ hemolytic function and $\mathrm{C} 3$ activation were blocked. Also, treated HA had a significantly increased binding of component C1q, C1r, C1s, C2, C5, C9, P, D and H. Further, when HA was gelfractionated by electrophoresis and then freeze-dried, its anticomplementary activity was stably induced. Both native and heated/freeze-dried HA stimulated ERK phosphorylation in prostate DU145 cells. However, treated HA suppressed the expression of tumor suppressors WOX1 and WOX2. Together, HA with an altered conformation stabilizes its inhibition and binding of complement proteins. It may recognize cell surface receptors differently from native HA, thereby differentially regulating the expression of cellular proteins.
\end{abstract}

\section{Introduction}

Hyaluronan (HA), or hyaluronic acid, is a connective tissue glycosaminoglycan (GAG), which provides physical

Correspondence to: Dr Nan-Shan Chang, Guthrie Research Institute, Laboratory of Molecular Immunology, 1 Guthrie Square, Sayre, PA 18840, USA

E-mail: nschang13827@yahoo.com

Key words: hyaluronan, complement, hemolysis, binding, WOX1, WWOX, DU145 protection and transport of nutrients to articular cartilage and supports cellular differentiation $(1,2)$. However, it acts as an enhancer of tumor invasion (3). HA participates in the initiation and progression of inflammation at both the cellular and extracellular levels (2,4-6).

The HA polymer is composed of repeating disaccharide units of $\beta$-glucuronic acid and $\mathrm{N}$-acetyl- $\beta$ - $\mathrm{D}$-glucosamine. In solution, high molecular size HA expands its domain $10^{3}-10^{4}$ times the volume of the polymer chain itself, and constitutes an ordered matrix conformation from a 4-fold left-handed helical structure (7-9). Large size macromolecules can be excluded from the matrix $(10,11)$. Interchain hydrogen bondings appear to contribute mainly to the ordered conformation.

It is generally agreed that naturally occurring polysulfated, GAGs, such as heparin, restrict complement activation via both the classical and alternative pathways more effectively than linear GAGs during inflammation (12-20). The potency of GAGs in inhibiting complement activation depends upon their extent and positions of polysulfation. Non-sulfated HA, even at high concentrations (1-5 mg/ml), could not restrict complement activation $(19,20)$.

We have shown that alteration of HA conformation with heat transiently induces its inhibition on complement activation of the classical pathway $(19,20)$. For example, HA in solution was heated at $100^{\circ} \mathrm{C}$ for 5-30 min, followed by snapfreezing and thawing promptly prior to interacting with serum complement. This led to a dramatic augmentation of HA inhibition of complement hemolytic function $(19,20)$. However, the induced activity was readily lost when the heated HA was slowly cooled, or the heated/snapfrozen HA was slowly thawed before interacting with the serum complement. Presumably, the transient interchain decoupling of the HA polymer allows exposure of polyanionic charges for binding with complement proteins. This inhibitory activity is reversible and re-inducible $(19,20)$.

In this study, we determined that HA, when subjected to heat treatment and freeze-drying, stabilized its anticomplementary activity by selectively interacting with complement C1q, C1r, C1s, C2, C5, C9, factor P, D and H. These proteins are in the initial and end phases of complement activation of both the classical and alternative pathways. We 
examined the effect of these HA preparations on the phosphorylation of extracellular signal-regulated kinase (ERK) (21) and on the expression of WW domain-containing oxido-reductase WOX1 (also named WWOX or FOR) and WOX2 (22-24; reviews), in prostate DU145 cells. The conformational alteration of HA related with heat treatment and freeze-drying, along with its effect on cell functions, are discussed.

\section{Materials and methods}

HA preparations. Six hundred $\mu 1$ of $3 \mathrm{mg} / \mathrm{ml} \mathrm{HA} \mathrm{(molecular}$ weight $10^{5}-10^{6}$; Sigma-Aldrich) in distilled water was heated for $20 \mathrm{~min}$ at $100^{\circ} \mathrm{C}$, and then either slowly cooled (sc) at room temperature for $30 \mathrm{~min}$ or quickly frozen $(q f)$ in an acetone-dry ice bath prior to freeze-drying $(f d)$. Unheated HA samples were considered as 'native' controls. Several HA preparations were as follows: i) $\mathrm{HA}_{n}$, native $\mathrm{HA}$; ii) $\mathrm{HA}_{n f d}$, HA subjected to freeze-drying; iii) $\mathrm{HA}_{s c f d}$, HA heat-treated followed by slow cooling and freeze-drying, and 4) $\mathrm{HA}_{\text {qffd }}$, HA heat-treated followed by quick freezing and freezedrying. Similar HA preparations were made using medical grade Healon (highly purified and high molecular size), a kind gift from Dr G. Armand of the Glycomed Research, Hastings-on-Hudson, New York.

Kinetic complement hemolytic tests. Complement hemolytic assay of the classical pathway was performed as described $(19,20)$. Aliquots of the above HA preparations $(600 \mu \mathrm{g} / \mathrm{ml})$ were mixed with an equal volume of diluted normal human serum (NHS; 1/30-1/120 dilutions in a metal-gelatin-veronal $\mathrm{GVB}^{++}$buffer), incubated at $37^{\circ} \mathrm{C}$ for $10 \mathrm{~min}$, and then added to prewarmed $\left(37^{\circ} \mathrm{C}\right) \mathrm{EA}$ cells $\left(2 \times 10^{7}\right.$ cells $/ \mathrm{ml}$ of sheep erythrocytes coated with antibodies and suspended in $\mathrm{GVB}^{++}$). Continuous measurement of complement-mediated hemolysis was performed at $37^{\circ} \mathrm{C}$ using a kinetic spectrophotometer and a thermal 96-well microplate scanner (Tecan Rainbow/Thermo), and inhibition of hemolysis by HA was calculated as described $(19,20)$.

In addition, the freeze-dried HA polymers were directly mixed with neat serum and diluted to a final concentration of $3 \mathrm{mg} / \mathrm{ml} \mathrm{HA}$ and 1/3 dilution of the serum. The HA/serum ratio was similar to that in the synovial fluid (25). These mixtures were incubated at $37^{\circ} \mathrm{C}$ for $2 \mathrm{~h}$ with constant rotation for dissolving the HA polymers in the serum. The mixtures were further diluted (1/30-1/120 final dilutions) and incubated with prewarmed EA cells for determining the kinetics of EA lysis as described above.

The effect of HA preparations on the hemolytic activity of serum C1 was also examined $(19,20)$. Briefly, the above $\mathrm{HA} /$ serum mixtures were diluted to $1 / 6000-1 / 24000$, to such an extent that the serum $\mathrm{C} 1$ became a rate-limiting factor for the lysis of EA cells coated with excess amounts of C4, C2 and C3-C9 $(19,20)$. The diluted serum/HA mixtures were prewarmed at $37^{\circ} \mathrm{C}$ for $10 \mathrm{~min}$, followed by stepwise additions and incubations with excess amounts of EAC4, C2 and C3$\mathrm{C} 9$, and the kinetics of HA-mediated inhibition of $\mathrm{C} 1$ hemolytic function was measured. In controls, serum alone was diluted to the same extent prior to testing the serum $\mathrm{C} 1$ hemolytic function.
Determination of C3 activation. We examined whether HA preparations prevented or induced serum C3 activation. Aliquots of NHS were $1 / 5$ diluted (in the $\mathrm{GVB}^{++}$buffer) in the presence or absence of heat-aggregated human $\operatorname{IgG}(1 \mathrm{mg} /$ $\mathrm{ml})$ to activate the complement, followed by adding $600 \mu \mathrm{g} /$ $\mathrm{ml}$ of $\mathrm{HA}_{n}, \mathrm{HA}_{n f d}, \mathrm{HA}_{s c f d}, \mathrm{HA}_{q f f d}$, or buffer only. The mixtures were incubated for $1 \mathrm{~h}$ at $37^{\circ} \mathrm{C}$ and processed for crossedimmunoelectrophoresis using anti-C3 antibodies (Calbiochem/ EMD Biosciences). The extent of $\mathrm{C} 3$ activation or conversion was calculated $(19,20)$.

Binding of complement components by HA preparations. HA preparations (25-400 ng) were dot-blotted onto a Zeta-probe nylon membrane using a dot-blot apparatus (BioRad). The membrane was saturated with $5 \%$ non-fat dried milk to block non-specific binding sites, and added to $2 \mathrm{ml}$ of 1/100 diluted NHS (in EDTA-containing VBS buffer to prevent $\mathrm{C} 1$ activation) for incubation at $4^{\circ} \mathrm{C}$ for $2 \mathrm{~h}$. Following washing of the membrane ( 3 times) with phosphate-buffered saline (PBS; $10 \mathrm{~min}$ each), specific antibodies were added. These antibodies were anti-C1q, C1r, C1s, C2, C4, C3, C5, C6, C7, C8, C9, B, D, P, H, C1 inhibitor, S-protein (vitronectin) (Calbiochem/EMD Biosciences), and serum histidine/proline-rich glycoprotein (HPRG) (26), respectively. The membrane bound IgG antibodies were detected by the binding of $\left[{ }^{125} \mathrm{I}\right]$-protein A (Amersham Biosciences/GE Healthcare).

In additional experiments, HA preparations were coated overnight onto 96-well ELISA microtiter plates $(1 \mu \mathrm{g} / \mathrm{well}$; Corning), followed by washing the plates with PBS, blocking non-specific binding sites with albumin $(1 \mathrm{mg} / \mathrm{ml})$, and adding aliquots of $1 / 100$ diluted NHS to the wells for incubation at $4^{\circ} \mathrm{C}$ for $30 \mathrm{~min}$. The extent of equal binding of HA to the microtiter plates was determined by staining HA with Alcian blue, and by ELISA using a monoclonal antibody against human trophoblast protein (MCA227; Serotech), which is known to recognize HA (27). Binding of serum complement components by the coated HA preparations was determined by standard ELISA, using the above-mentioned antibodies.

HA preparative polyacrylamide gel electrophoresis. Native HA samples $(3 \mathrm{mg}$ ) were fractionated according to their molecular sizes by electrophoresis in a $10 \%$ non-SDS preparative polyacrylamide gel. The majority of HA molecules were distributed at the upper portion of the entire gel as detected by the Schiff's reagent or Alcian blue (Sigma). The HA containing portion was sliced equally into an upper and a lower half according to the molecular sizes of HA, designated gel 1 and gel 2, and the HA molecules were then electroeluted from these gels using a BioRad electroelutor. The isolated HA samples from gel 1 and 2 were subjected to treatments with heat, snapfrozen and/or freeze-dried as described above. These HA preparations were tested for their inhibition of complement-mediated EA hemolysis $(19,20)$.

Hyaluronidase digestion of HA. Where indicated, HA preparations were treated with bovine testicular hyaluronidase (20 units/ml, Sigma) at various times at room temperature, followed by heat treatment $\left(100^{\circ} \mathrm{C}, 2 \mathrm{~min}\right)$ to inactivate 
$\boldsymbol{A}$.

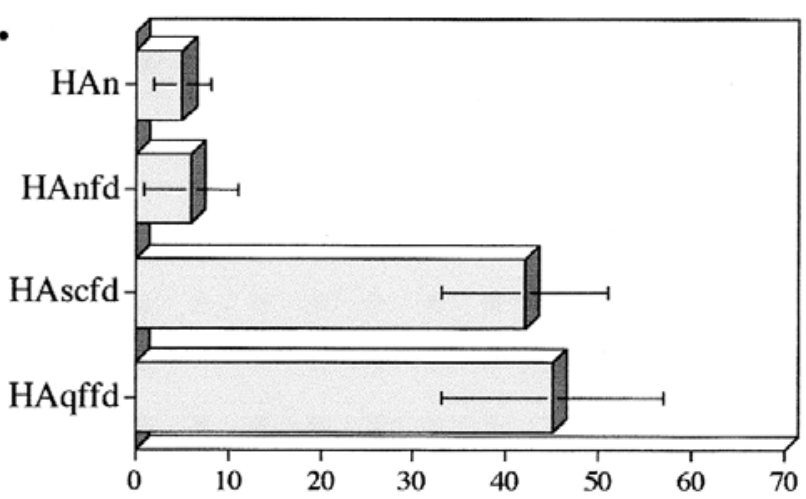

$\%$ Inhibition of EA Hemolysis

B.

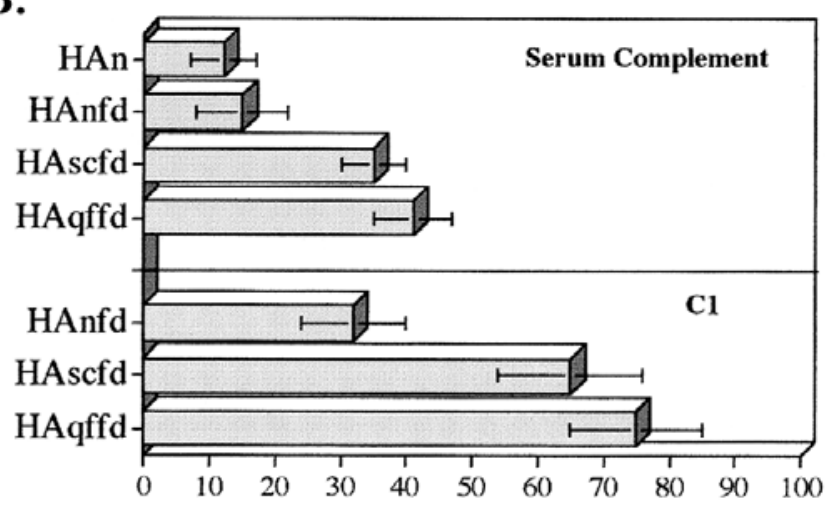

$\%$ Inhibition of Hemolysis

Figure 1. Heat-treated/freeze-dried HA inhibits complement hemolytic function. (A) HA samples were prepared as described in Materials and methods. Diluted human serum was incubated with the indicated HA preparations for $10 \mathrm{~min}$ at $37^{\circ} \mathrm{C}$, followed by the addition of prewarmed EA cells (sheep erythrocytes coated with antibodies). Each result represents an average and standard deviation of 5 experiments $(n=5)$. Heated/freeze-dried $\mathrm{HA}$ inhibited complement hemolytic function. $\mathrm{HA}_{n}$, native $\mathrm{HA} ; \mathrm{HA}_{n f d}$, native $\mathrm{HA}$ in solution subjected to freeze-drying; $\mathrm{HA}_{\text {scfd }}$, $\mathrm{HA}$ heat-treated followed by slow cooling and freeze-drying; and $\mathrm{HA}_{q f f d}$, $\mathrm{HA}$ heat-treated followed by quick freezing and freeze-drying. Final dilutions: serum, 1/90; $\mathrm{HA}, 200 \mu \mathrm{g} / \mathrm{ml}$. Similar results were obtained when other dilutions of serum were used to interact with the HA preparations (data not shown). (B) Dried HA polymers, including $\mathrm{HA}_{n}, \mathrm{HA}_{n f d}, \mathrm{HA}_{\text {scfd }}$ and $\mathrm{HA}_{q f f d}$, were directly dissolved in serum by incubation for $2 \mathrm{~h}$ at $37^{\circ} \mathrm{C}$ ( $\mathrm{HA}, 3 \mathrm{mg} / \mathrm{ml}$; serum, 1/3 diluted). The HA/serum mixtures or diluted serum alone were further diluted to 1/90 for testing the hemolytic activity of the serum complement (against EA cells). The final concentration of HA was $100 \mu \mathrm{g} / \mathrm{ml}$. Similarly, these $\mathrm{HA} /$ serum mixtures or serum alone were diluted up to $1 / 6000$ for examining the rate-limiting serum $\mathrm{C} 1$ hemolytic function in the presence of EA cells coated with excess amounts of C4, C2, C3, and C5-C9 $(19,20)$. The final HA concentration was $1.5 \mu \mathrm{g} / \mathrm{ml}$. Again, heated/freeze-dried HA inhibited C1-initiated activation of the complement cascade for hemolysis.

hyaluronidase. The digested HA preparations were then tested for their activities on the restriction of the hemolytic functions of both whole serum complement and the functionally purified C1 $(19,20)$.

HA stimulates ERK phosphorylation in prostate DU 145 cells. Human prostate DU145 cells were cultured overnight in 100-mm Petri dishes (Corning), and then treated with the above mentioned HA preparations $(50 \mu \mathrm{g} / \mathrm{ml})$ for $1 \mathrm{~h}$ at $37^{\circ} \mathrm{C}$ culture. Phosphorylation and expression of ERK were examined by Western blotting. Antibody against ERK was

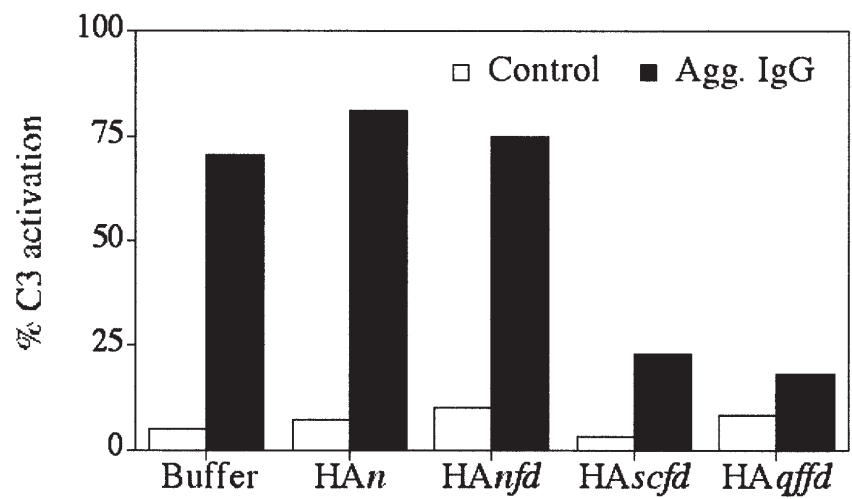

Figure 2. Heated/freeze-dried HA preparations inhibit serum C3 activation. Determination of human serum C3 activation or conversion by HA preparations, in the presence or absence of aggregated $\operatorname{IgG}$ (Agg. IgG), was performed as described in Materials and methods. Aggregated IgG was used to activate serum C3. Buffer alone was used in the negative control. Data shown are an average from 2 experiments.

from BD Transduction Laboratory, and antibody against phosphorylated-ERK (p-ERK) from Santa Cruz Laboratories. Antibodies against WOX1 and WOX2 were made in rabbits as described $(28,29)$.

\section{Results}

Heat-treated/freeze-dried HA inhibits complement activation. We previously demonstrated that HA anti-complementary activity could be induced when HA solutions were heated at $100^{\circ} \mathrm{C}$ for 5-30 min, followed by snapfreezing and thawing just prior to interaction with the serum complement $(19,20)$. Without snapfreezing and prompt thawing, no induced anticomplementary activity was observed. Here, we showed that the heat-induced HA anti-complementary activity was stabilized by freeze-drying. HA solutions were preheated at $100^{\circ} \mathrm{C}$ for $20 \mathrm{~min}$, followed by slow cooling and freezedrying $\left(\mathrm{HA}_{\text {scfd }}\right)$, or by quick freezing and freeze-drying $\left(\mathrm{HA}_{q f f d}\right)$. Aliquots of these HA preparations were incubated with diluted NHS for $10 \mathrm{~min}$ at $37^{\circ} \mathrm{C}$, which resulted in $\sim 45 \%$ inhibition of serum complement-mediated hemolysis of EA cells (sheep erythrocytes coated with antibodies; Fig. 1A). In contrast, unheated or native HA solutions with or without freeze-drying $\left(\mathrm{HA}_{n}\right.$ or $\left.\mathrm{HA}_{n f d}\right)$ failed to inhibit serum complement-mediated hemolysis (only 5\%). Notably, there was no significant difference between $\mathrm{HA}_{\text {scfd }}$ and $\mathrm{HA}_{\text {qffd }}$ in the inhibition of complement function ( $\mathrm{p}>0.5$, Student's t-tests). Similarly, heated HA solutions, when subjected to slow cooling $\left(\mathrm{HA}_{s c}\right)$, also failed to restrict complement-mediated EA hemolysis $(<10 \%)$. The inhibitory effect on EA hemolysis by $\mathrm{HA}_{\text {scfd }}$ and $\mathrm{HA}_{\text {qffd }}$ was not due to $\mathrm{C} 3$ consumption or activation by these HA preparations, as determined by $\mathrm{C} 3$ crossed-immunoelectrophoresis (Fig. 2). These observations were reproduced using medical grade or highly purified Healon (data not shown), indicating the specific effects of $\mathrm{HA}$ on the complement, rather than on protein contamination in the HA from Sigma.

Also, the freeze-dried HA polymers, with or without heat treatment, were directly dissolved in $1 / 3$ diluted serum for $2 \mathrm{~h}$ 
A.

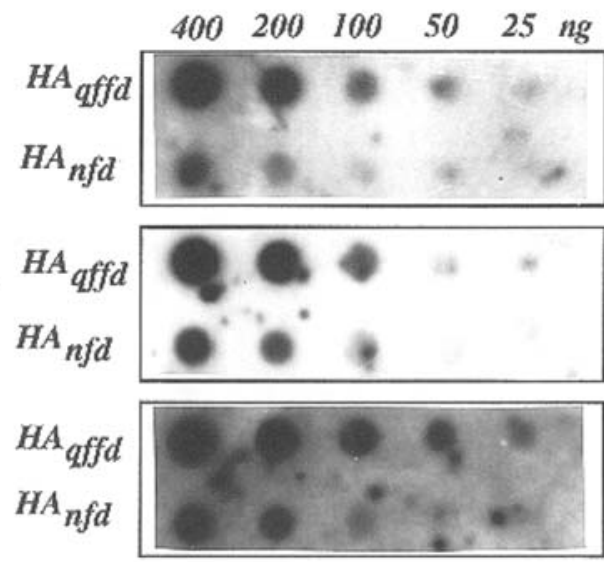

$\boldsymbol{B}$.

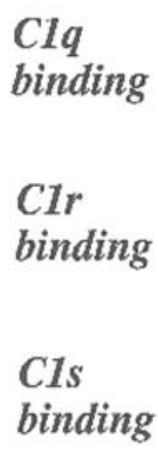

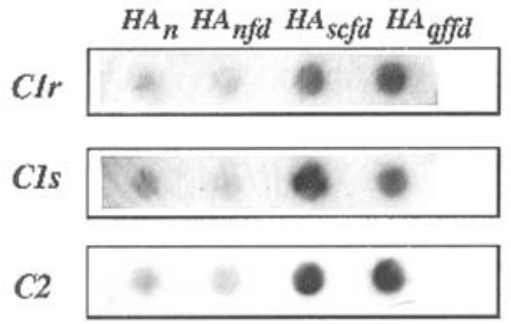
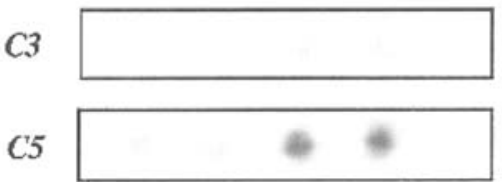

C9

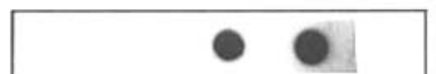

Figure 3. Binding of serum complement proteins by conformationally altered HA. (A) $\mathrm{HA}_{n f d}$ and HA $\mathrm{H}_{\text {qfd }}$ samples (25-400 ng) were immobilized onto a nylon membrane and incubated with $1 / 100$ diluted normal human serum, followed by processing immunostaining using antibodies against $\mathrm{C} 1 \mathrm{q}$, $\mathrm{C} 1 \mathrm{r}$ and $\mathrm{C} 1 \mathrm{~s}$ (see Materials and methods). (B) Similarly, binding of serum complement proteins to immobilized HA preparations, including $\mathrm{HA}_{n}$, $\mathrm{HA}_{n f d}, \mathrm{HA}_{s f f d}$ and $\mathrm{HA}_{q f f d}(100$ ng), was performed. Antibodies used were anti-C1r, C1s, C2, C3, C5, and C9.

Table I. Inhibition of complement hemolysis by gelfractionated/freeze-dried HA. ${ }^{\mathrm{a}}$

$\%$ Inhibition of serum complement hemolytic activity

\begin{tabular}{lll}
\cline { 2 - 3 } & Gel 1 & Gel 2 \\
\hline $\mathrm{HA}_{e}$ & 11.3 & 12.7 \\
$\mathrm{HA}_{\text {efd }}$ & 56.2 & 59.1 \\
$\mathrm{HA}_{\text {escfd }}$ & 61.5 & 59.6 \\
$\mathrm{HA}_{\text {eqffd }}$ & 59.8 & 57.7 \\
\hline
\end{tabular}

${ }^{a}$ Native HA in solution was electrophoresed in a non-SDS polyacrylamide gel. The HA-containing portion was sliced equally into an upper and a lower half, namely gel 1 and gel 2, followed by electroelution. The eluted HA $\left(\mathrm{HA}_{e}\right)$ samples were then i) freeze-dried $\left(\mathrm{HA}_{\text {efd }}\right)$, ii) heated, slow-cooled and freeze-dried $\left(\mathrm{HA}_{\text {escfd }}\right)$, or iii) heated, snapfrozen and freeze-dried $\left(\mathrm{HA}_{\text {eqffd }}\right)$. Aliquots of the HA preparations were mixed with equal volumes of diluted serum and incubated for $10 \mathrm{~min}$ at $37^{\circ} \mathrm{C}$ prior to the addition of prewarmed EA cells. Final concentrations: HA preparations, $100 \mu \mathrm{g} / \mathrm{ml}$; serum, 1/90 diluted. The data represent an average of two experiments.

at $37^{\circ} \mathrm{C}$. Both $\mathrm{HA}_{s c f d}$ and $\mathrm{HA}_{\text {qffd }}$ inhibited the serum complement-mediated EA hemolysis more effectively than that of $\mathrm{HA}_{n}$ or $\mathrm{HA}_{n f d}(\mathrm{p}<0.01$; Student's t-tests) (Fig. 1B). Similarly, the HA/serum mixtures were further diluted to 1/6000 for titrating serum $\mathrm{C} 1$ hemolytic activity. The results also showed that both $\mathrm{HA}_{s c f d}$ and $\mathrm{HA}_{q f f d}$ exerted greater inhibitions on serum $\mathrm{C} 1$ than did $\mathrm{HA}_{n}$ or $\mathrm{HA}_{n f d}$ (Fig. 1B; data not shown for $\mathrm{HA}_{n}$ ).

In parallel with the above observations, aggregated IgG mediated $75 \%$ activation of serum $\mathrm{C} 3$, whereas this activation was reduced $\sim 20 \%$ by the presence of $\mathrm{HA}_{\text {scfd }}$ or $\mathrm{HA}_{q f f d}$ (Fig. 2).
Again, the above observed effects were not due to potential protein contamination in the HA preparations (from Sigma). Digestion of HA preparations with hyaluronidase readily abolished the stabilized anti-complementary activity e.g. from $80-90 \%$ of $\mathrm{C} 1$ inhibition from serum or purified $\mathrm{C} 1$ by $\mathrm{HA}_{s c f d}$ or $\mathrm{HA}_{q f f d}$, down to $<10 \%$ in a time- or dosedependent manner.

Gel-fractionated/freeze-dried HA inhibits complement hemolytic function. Gel fractionation by electrophoretic force is likely to induce interchain decoupling of the HA polymer similar to the effect of heat. HA in solution ( $3 \mathrm{mg}$ ) was electrophoresed in a polyacrylamide gel, followed by electroelution. These eluted HA preparations could not inhibit serum complement hemolytic function (Table I). However, these HA preparations were then freeze-dried and shown to have a significantly increased inhibition on complement-mediated EA hemolysis (Table I). Alternatively, these eluted HA fractions were heated, slowly cooled or quickly frozen, and then freeze-dried. These procedures yielded a similar extent of inhibition of hemolysis (Table I). That is, gel fractionation and freeze-drying are sufficient to induce an anti-complementary effect in HA.

Selective binding of complement proteins by heated/freezedried HA preparations. We determined whether heated/ freeze-dried HA has an increased binding affinity for complement proteins, thereby blocking their hemolytic function. Various amounts of $\mathrm{HA}_{n f d}$ and $\mathrm{HA}_{\text {qffd }}$ were immobilized onto a nylon membrane, followed by incubation with diluted human serum. Western blot analysis showed that $\mathrm{HA}_{\text {qffd }}$ had a significant increase $(>150 \%)$ in the binding of serum C1q, C1r and C1s, compared to that of $\mathrm{HA}_{n f d}$ (Fig. 3A). Similarly, a fixed amount of HA preparations was immobilized. There were significant increases $(>300 \%)$ in the binding of serum $\mathrm{C} 1 \mathrm{r}, \mathrm{C} 1 \mathrm{~s}, \mathrm{C} 2, \mathrm{C} 5$ and $\mathrm{C} 9$ by $\mathrm{HA}_{\text {scfd }}$ and $\mathrm{HA}_{q f f d}$, 
Table II. Binding of serum complement components by HA preparations. ${ }^{\mathrm{a}}$

\begin{tabular}{llccc}
\hline$\%$ Binding & $\mathrm{HA}_{n}$ & $\mathrm{HA}_{n f d}$ & $\mathrm{HA}_{s c f d}$ & $\mathrm{HA}_{q f f d}$ \\
\hline C1q & $0.0 \pm 2.6$ & $-3.9 \pm 10.4$ & $68.8 \pm 5.2$ & $74.0 \pm 15.6$ \\
C1r & $0.0 \pm 11.9$ & $4.5 \pm 2.4$ & $34.8 \pm 1.9$ & $44.1 \pm 8.5$ \\
C1s & $0.0 \pm 6.3$ & $-8.9 \pm 6.3$ & $17.9 \pm 5.4$ & $26.8 \pm 7.1$ \\
C2 & $0.0 \pm 9.2$ & $-1.3 \pm 6.1$ & $30.1 \pm 7.9$ & $37.8 \pm 11.9$ \\
C4 & $0.0 \pm 5.6$ & $-5.4 \pm 5.4$ & $-2.7 \pm 5.2$ & $-3.6 \pm 4.7$ \\
C3 & $0.0 \pm 5.6$ & $-5.5 \pm 3.7$ & $5.5 \pm 10.2$ & $10.7 \pm 5.4$ \\
C5 & $0.0 \pm 7.5$ & $-4.1 \pm 8.4$ & $19.3 \pm 6.6$ & $18.2 \pm 4.0$ \\
C6 & $0.0 \pm 4.3$ & $2.2 \pm 9.7$ & $13.0 \pm 7.6$ & $16.8 \pm 9.2$ \\
C7 & $0.0 \pm 12.0$ & $-1.8 \pm 7.8$ & $5.5 \pm 4.6$ & $11.1 \pm 4.1$ \\
C8 & $0.0 \pm 3.1$ & $-12.5 \pm 9.4$ & $3.1 \pm 7.0$ & $7.0 \pm 4.7$ \\
C9 & $0.0 \pm 7.2$ & $-2.8 \pm 8.9$ & $25.0 \pm 8.1$ & $30.6 \pm 6.9$ \\
P & $0.0 \pm 6.2$ & $-1.5 \pm 9.7$ & $53.6 \pm 5.6$ & $69.8 \pm 9.5$ \\
B & $0.0 \pm 3.9$ & $-1.7 \pm 3.8$ & $-2.6 \pm 5.6$ & $-0.4 \pm 3.6$ \\
H & $0.0 \pm 9.1$ & $1.3 \pm 6.5$ & $16.3 \pm 2.2$ & $22.4 \pm 6.0$ \\
D & $0.0 \pm 11.1$ & $-1.0 \pm 4.8$ & $22.1 \pm 6.9$ & $24.3 \pm 9.1$ \\
C1 inhibitor & $0.0 \pm 11.4$ & $5.0 \pm 7.0$ & $11.4 \pm 4.4$ & $8.9 \pm 4.4$ \\
S-protein & $0.0 \pm 0.5$ & $0.1 \pm 0.7$ & $-0.2 \pm 10.4$ & $0.3 \pm 0.2$ \\
HPRG & $0.0 \pm 1.1$ & $0.1 \pm 1.4$ & $4.0 \pm 6.5$ & $-0.2 \pm 1.3$ \\
\hline
\end{tabular}

${ }^{a}$ Binding of serum complement components to HA preparations was performed as described in Materials and methods. By normalizing to $\mathrm{HA}_{n}$ (regarded as a background binding), both $\mathrm{HA}_{s c f d}$ and $\mathrm{HA}_{q f f}$ had significant increases in the binding of serum complement $\mathrm{C} 1 \mathrm{q}, \mathrm{C} 1 \mathrm{r}$, $\mathrm{C} 1 \mathrm{~s}, \mathrm{C} 2, \mathrm{C} 5, \mathrm{C} 9, \mathrm{D}, \mathrm{P}$, and $\mathrm{H}$ (p<0.01, n=8, Student's t-tests). No significant increases in the binding of C4, C3, C6, C7, C8, B, C1 inhibitor, S-protein and HPRG to $\mathrm{HA}_{s c f d}$ and $\mathrm{HA}_{\text {qffd }}$ were observed compared to the $\mathrm{HA}_{n}$ controls ( $>0.5, \mathrm{n}=8$, Student's t-tests). Moreover, there were no significant differences in the binding of complement proteins between $\mathrm{HA}_{n}$ and $\mathrm{HA}_{n f d}\left(\mathrm{p}>0.5, \mathrm{n}=8\right.$, Student's t-test). ${ }^{\mathrm{b}} \mathrm{HPRG}$ : Histidine/ proline-rich glycoprotein, also known as histidine-rich glycoprotein (26).

\section{DU145}

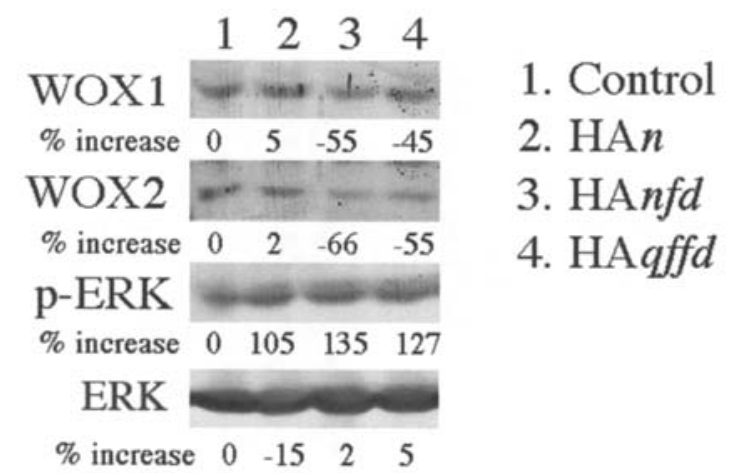

Figure 4. Regulation of ERK phosphorylation and WOX1 and WOX2 expression by HA preparations. Human prostate DU145 cells were cultured overnight in Petri dishes and then treated with buffer or HA preparations, including $\mathrm{HA}_{n}, \mathrm{HA}_{n f d}$ and $\mathrm{HA}_{q f f d}(50 \mu \mathrm{g} / \mathrm{ml})$ for $1 \mathrm{~h}$ at $37^{\circ} \mathrm{C}$. These HA preparations equally increased ERK phosphorylation, whereas $\mathrm{HA}_{n f d}$ and $\mathrm{HA}_{\text {qffd }}$ suppressed the expression of candidate tumor suppressors WOX1 (46 kDa; wild-type) and WOX2 (41 kDa; truncated) (27-29). These HA preparations had no effect on tumor suppressor p53 (data not shown). A set of representative data is shown from 3 experiments.

compared to $\mathrm{HA}_{n}$ and $\mathrm{HA}_{n f d}$ (Fig. 3B). These HA preparations did not bind C3 (Fig. 3B). In these experiments, NHS was diluted in the presence of EDTA to prevent complement activation.
We further confirmed the above observations by ELISA. Compared to buffer controls, $\mathrm{HA}_{n}$ had $<10 \%$ increases in the binding of complement proteins (thus regarded as zero or background). By normalizing to $\mathrm{HA}_{n}$, both $\mathrm{HA}_{s c f d}$ and $\mathrm{HA}_{q f f d}$ had significant increases in the binding of serum complement C1q, C1r, C1s, C2, C5, C9, D, P, and H (Table II) (p<0.01, $\mathrm{n}=8$, Student's t-tests). However, there were no significant increases in the binding of complement $\mathrm{C} 4, \mathrm{C} 3, \mathrm{C} 6, \mathrm{C} 7, \mathrm{C} 8, \mathrm{~B}$, $\mathrm{C} 1$ inhibitor, S-protein and histidine/proline-rich glycoprotein by $\mathrm{HA}_{\text {scfd }}$ and $\mathrm{HA}_{q f f d}$, compared to the control $\mathrm{HA}_{n}$ binding $(\mathrm{p}>0.1, \mathrm{n}=8)$. Similarly, $\mathrm{HA}_{n f d}$ had little or no increases in the binding of complement proteins.

Positive coating of HA preparations to nylon membranes and ELISA microtiter plates was confirmed by Alcian blue staining. Also, we utilized a monoclonal antibody in ELISA. This antibody recognizes a human trophoblast protein and HA (27). Our data showed that relatively constant amounts of HA preparations were coated onto the nylon membranes and ELISA microtiter plates (data not shown).

Heated/freeze-dried HA increases ERK phosphorylation but suppresses the expression of WOX1 and WOX 2 in prostate DU145 cells. Cancer invasion is frequently associated with upregulation of HA and hyaluronidases $(3,30,31)$. Conformational alteration of HA is likely to occur under cancer-related inflammation in vivo $(3,30,31)$. HA induces activation of the MEK-ERK signaling cascade via the 
receptor for HA-mediated motility (RHAMM) (21). We examined whether there was an altered ERK phosphorylation in human prostate DU145 cells in response to conformationally altered HA. All the tested HA preparations, including $\mathrm{HA}_{n}, \mathrm{HA}_{n f d}$ and $\mathrm{HA}_{q f f d}$, equally increased ERK phosphorylation during $1 \mathrm{~h}$ of exposure (Fig. 4A). In contrast, $\mathrm{HA}_{n f d}$ and $\mathrm{HA}_{\text {qffd }}$ suppressed the expression of candidate tumor suppressors WOX1 (46 kDa; wild-type) and WOX2 (41 kDa; truncated) $(28,29)$. These HA preparations had no effect on tumor suppressor p53 (data not shown). Similar results were observed during a prolonged exposure of 16-24 h, or in a dose-related experiment.

\section{Discussion}

In agreement with our previous observations $(19,20)$, the HA anti-complementary activity can be induced by altering its conformation in solutions. By freeze-drying heated HA solutions, we stabilized the HA anti-complementary activity, as evidenced by a significant increase in the inhibition of serum complement hemolytic function. This inhibition was due to prevention of serum $\mathrm{C} 1$ activation by the heated/ freeze-dried HA preparations. Indeed, these treated HA preparations blocked aggregated IgG-induced serum $\mathrm{C} 3$ activation. Binding studies showed that these $\mathrm{HA}$ preparations, i.e. $\mathrm{HA}_{s c f d}$ and $\mathrm{HA}_{q f f d}$, bound $\mathrm{C} 1 \mathrm{q}, \mathrm{C} 1 \mathrm{r}, \mathrm{C} 1 \mathrm{~s}, \mathrm{C} 2$, C5 and C9 of the classical pathway, indicating their restriction of complement activation via interacting with these complement proteins. Moreover, inhibition of serum $\mathrm{C} 1$ hemolytic function by these HA preparations suggests that $\mathrm{C} 1$ activation is restricted and the assembly of $\mathrm{C} 4 \mathrm{~b} 2 \mathrm{a}$ and subsequent $\mathrm{C} 3$ activation is blocked.

A plausible explanation for the stabilized HA anticomplementary activity is that freeze-drying causes partial depolymerization of HA long chains (32), which occurs as a result of generation of free radicals during lyophilization or freeze-drying. The depolymerized HA short segments when re-coupled with HA long chains may disrupt the intact HA network (33-36), thereby generating a disordered HA conformation. Consequently, complement proteins become readily restricted by $\mathrm{HA}$ via binding to its accessible polyanionic charges within the disrupted matrix.

To simulate heat-induced chain decoupling, we fractionated the HA polymer by electrophoresis in polyacrylamide gels. The gel-fractionated HA was weakly anticomplementary, and its activity was greatly augmented upon freeze-drying, even without heating. Again, these observations substantiate our notion that during electrophoresis and freezedrying, HA undergoes chain-decoupling and partial depolymerization, which are essential for the generation of an enhanced anti-complementary activity.

We assessed the effect of HA preparations on ERK activation in metastatic prostate DU145 cells. HA activates the MEK-ERK signaling cascade via cell surface RHAMM (21). Both native and heated/freeze-dried HA preparations induced ERK phosphorylation, suggesting that all the HA samples bind RHAMM. However, the treated HA suppressed the expression of proapoptotic WOX1 and WOX2. This suppression is probably due to the recognition of additional types of cell surface receptors by the conformationally altered
HA, thereby altering cellular protein expression. Hyaluronidases are known to induce the expression of WOX1 $(22-24,37,38)$, and are expected to counteract with HA for this induction.

Heated/freeze-dried HA selectively interacts with several but not all the complement proteins. $\mathrm{HA}_{\text {scfd }}$ and $\mathrm{HA}_{q f f d}$ effectively bind C1q, C1r, C1s, C2, C5, C9, P, D and H, whereas they have no apparent binding interactions with $\mathrm{C} 3$, C4, B, S-protein (vitronectin) and histidine/proline-rich glycoprotein. In contrast, heparin interacts with $\mathrm{C} 1 \mathrm{q}, \mathrm{C} 2, \mathrm{C} 4$, C4-binding protein, $\mathrm{C} 1$ inhibitor, $\mathrm{B}, \mathrm{D}, \mathrm{H}, \mathrm{P}, \mathrm{C} 6, \mathrm{C} 8$, and $\mathrm{C} 9$ (39). The differential reactivity with complement proteins between heparin and the conformationally altered HA is mainly due to their differences in the extent of sulfation. The structural motifs in the above complement proteins, which are recognized by the conformationally altered HA are unknown and remain to be elucidated.

Native HA molecules bind to a structural motif in the HA-binding proteins, such as RHAMM, CD44 and link proteins (40). This motif contains a sequence of $\mathrm{B}(\mathrm{X} 7) \mathrm{B}$, where $\mathrm{B}$ is either arginine or lysine, and X7 is a stretch of seven amino acids containing no acidic residue and at least one basic amino acid. We have analyzed the sequences of mouse C1q A, B, C chains and human factor P; however, no such structural motif has been found in these proteins. These observations indicate that both native and conformationally altered HA bind to different structural motifs in proteins.

To extensively disrupt the ordered HA conformation, HA was subjected to depolymerization by hyaluronidase. The results showed that there was a significant decrease in the $\mathrm{C} 1$ functional restriction by the depolymerized HA. Apparently, hyaluronidase extensively depolymerized HA down to small oligosaccharide units, which is different from that of the degrading effect of freeze-drying. Since the short HA oligosaccharides have poor regulatory activity against the complement, it is suggested that the restriction of $\mathrm{C} 1$ by HA requires a certain extent of polymerization of HA disaccharide units in order to bind and fold around $\mathrm{C} 1$ molecules.

In summary, we have shown in this study that HA anticomplementary activity can be stabilized by heat treatment and freeze-drying. This treated HA may have therapeutic values in suppressing complement-induced inflammatory diseases. We believe that an anti-inflammatory module in HA does exist, and that further design is required to maximize its function in controlling complement function and cell growth and death.

\section{Acknowledgments}

This work was supported in part by the Guthrie Foundation for Education and Research.

\section{References}

1. Ghosh P: The role of hyaluronic acid (hyaluronan) in health and disease: interactions with cells, cartilage and components of synovial fluid. Clin Exp Rheumatol 12: 75-82, 1994.

2. Taylor KR and Gallo RL: Glycosaminoglycans and their proteoglycans: host-associated molecular patterns for initiation and modulation of inflammation. FASEB J 20: 9-22, 2006.

3. Toole BP: Hyaluronan promotes the malignant phenotype. Glycobiology 12: 37R-42R, 2002. 
4. Siegelman MH, DeGrendele $\mathrm{HC}$ and Estess P: Activation and interaction of CD44 and hyaluronan in immunological systems. J Leukoc Biol 66: 315-321, 1999.

5. Pure E and Cuff CA: A crucial role for CD44 in inflammation. Trends Mol Med 7: 213-221, 2001.

6. Lisignoli G, Cristino S, Piacentini A, Cavallo C, Caplan AI and Facchini A: Hyaluronan-based polymer scaffold modulates the expression of inflammatory and degradative factors in mesenchymal stem cells: Involvement of Cd44 and Cd54. J Cell Physiol 207: 364-373, 2005.

7. Almond A, Deangelis PL and Blundell CD: Hyaluronan: the local solution conformation determined by NMR and computer modeling is close to a contracted left-handed 4-fold helix. J Mol Biol 358: 1256-1269, 2006.

8. Furlan S, La Penna G, Perico A and Cesaro A: Hyaluronan chain conformation and dynamics. Carbohydr Res 340: 959-970, 2005.

9. Hadler NM, Dourmashkin RR, Nermut MV and Williams LD: Ultrastructure of a hyaluronic acid matrix. Proc Natl Acad Sci USA 79: 307-309, 1982.

10. Asteriou T, Vincent JC, Tranchepain F and Deschrevel B: Inhibition of hyaluronan hydrolysis catalysed by hyaluronidase at high substrate concentration and low ionic strength. Matrix Biol 25: 166-174, 2006.

11. Sabaratnam S, Arunan V, Coleman PJ, Mason RM and Levick JR: Size selectivity of hyaluronan molecular sieving by extracellular matrix in rabbit synovial joints. J Physiol 567: 569-581, 2005.

12. Yu H, Munoz EM, Edens RE and Linhardt RJ: Kinetic studies on the interactions of heparin and complement proteins using surface plasmon resonance. Biochim Biophys Acta 1726: $168-176,2005$

13. Wuillemin WA, de Velthuis H, Lubbers YTP, de Ruig CP, Eldering $\mathrm{E}$ and Hack CE: Potentiation of $\mathrm{C} 1$ inhibitor by glycosaminoglycans: dextran sulfate species are effective inhibitors of in vitro complement activation in plasma. J Immunol 159: 1953-1960, 1997.

14. De Messias IT, Mohren D and Kajdacsy-Balla A: Inhibition of the classical and alternative pathways of the human complement system by glycosaminoglycan polysulfate. J Investig Allergol Clin Immunol 4: 172-176, 1994.

15. Meri S and Pangburn MK: Regulation of alternative pathway complement activation by glycosaminoglycans: specificity of the polyanion binding site on factor $\mathrm{H}$. Biochem Biophys Res Commun 198: 52-59, 1994.

16. Ekre HP, Naparstek Y, Lider O, Hyden P, Hagermark O, Nilsson T, Vlodavsky I and Cohen I: Anti-inflammatory effects of heparin and its derivatives: inhibition of complement and of lymphocyte migration. Adv Exp Med Biol 313: 329-340, 1992.

17. Caughman GB, Boackle RJ and Vesely J: A postulated mechanism for heparin's potentiation of $\mathrm{C} 1$ inhibitor function. Mol Immunol 19: 287-295, 1982.

18. Almeda S, Rosenberg RD and Bing DH: The binding properties of human complement component C1q. Interaction with mucopolysaccharides. J Biol Chem 258: 785-791, 1983.

19. Chang N-S, Boackle RJ and Armand G: Hyaluronic acidcomplement interactions-I. Reversible heat-induced anticomplementary activity. Mol Immunol 22: 391-397, 1985.

20. Chang N-S and Boackle RJ: Hyaluronic acid-complement interactions-II. Role of divalent cations and gelatin. Mol Immunol 22: 843-848, 1985

21. Zhang S, Chang MC, Zylka D, Turley S, Harrison R and Turley EA: The hyaluronan receptor RHAMM regulates extracellular-regulated kinase. J Biol Chem 273: 11342-11348, 1998.
22. Richards RI: Fragile and unstable chromosomes in cancer: causes and consequences. Trends Genet 17: 339-345, 2001.

23. Chang N-S: A potential role of p53 and WOX1 in mitochondrial apoptosis (Review). Int J Mol Med 9: 19-24, 2002.

24. Chang N-S, Doherty J, Ensign A, Lewis J, Heath J, Schultz L, Chen ST and Oppermann U: Molecular mechanisms underlying WOX1 activation during apoptotic and stress responses. Biochem Pharmacol 66: 1347-1354, 2003.

25. Poortmans JR, S'jongers J-J and Bidon G: Distribution of plasma proteins and hyaluronic acid in synovial fluid and serum of human subjects in hydarthrosis. Clin Chem Acta 55: 205-209, 1974

26. Chang N-S, Leu RW, Rummage JA, Anderson JK and Mole JE: Regulation of complement functional efficiency by histidinerich glycoprotein. Blood 79: 2973-2980, 1992.

27. Sunderland CA, Redman CW and Stirrat GM: Monoclonal antibodies to human syncytiotrophoblast. Immunology 43: 541-546, 1981.

28. Chang N-S, Pratt N, Heath J, Schultz L, Sleve D, Carey GB and Zevotek N: Hyaluronidase induction of a WW domaincontaining oxidoreductase that enhances tumor necrosis factor cytotoxicity. J Biol Chem 276: 3361-3370, 2001

29. Sze CI, Su M, Pugazhenthi S, Jambal P, Hsu LJ, Heath J, Schultz L and Chang N-S: Downregulation of WOX1 induces Tau phosphorylation in vitro: A potential role in Alzheimer's disease. J Biol Chem 279: 30498-30506, 2004.

30. Stern R: Hyaluronan metabolism: a major paradox in cancer biology. Pathol Biol (Paris) 53: 372-382, 2005.

31. Toole BP: Hyaluronan: from extracellular glue to pericellular cue. Nat Rev Cancer 4: 528-539, 2004.

32. Wedlock DJ, Phillips GO, Davies A, Gormally J and Wyn-Jones E Depolymerization of sodium hyaluronate during freeze-drying. Int J Biol Macromol 5: 186-188, 1983.

33. Welsh EJ, Rees DA, Morris ER and Madden JK: Competitive inhibition evidence for specific intermolecular interactions in hyaluronate solutions. J Mol Biol 138: 375-382, 1980.

34. Morris ER, Rees DA and Welsh EJ: Conformation and dynamic interactions in hyaluronate solutions. J Mol Biol 138: 383-400, 1980.

35. Scott JE and Heatley F: Biological properties of hyaluronan in aqueous solution are controlled and sequestered by reversible tertiary structures, defined by NMR spectroscopy. Biomacromolecules 3: 547-553, 2002.

36. Cowman MK and Matsuoka S: Experimental approaches to hyaluronan structure. Carbohydr Res 340: 791-809, 2005.

37. Lokeshwar VB, Cerwinka WH, Isoyama T and Lokeshwar BL: HYAL1 hyaluronidase in prostate cancer: a tumor promoter and suppressor. Cancer Res 65: 7782-7789, 2005.

38. Chang N-S: Transforming growth factor-beta 1 blocks the enhancement of tumor necrosis factor cytotoxicity by hyaluronidase Hyal-2 in L929 fibroblasts. BMC Cell Biol 3: 8, 2002.

39. Sahu A and Pangburn MK: Identification of multiple sites of interaction between heparin and the complement system. Mol Immunol 30: 679-684, 1993.

40. Yang B, Yang BL, Savani RC and Turley EA: Identification of a common hyaluronan binding motif in the hyaluronan binding proteins RHAMM, CD44 and link protein. EMBO J 13: 286-296, 1994. 